\title{
Risk factors associated with overweight and obesity among urban school children and adolescents in Bangladesh: a case-control study
}

\author{
Mejbah Uddin Bhuiyan ${ }^{1,2^{*}}$, Shahaduz Zaman ${ }^{1,3}$ and Tahmeed Ahmed ${ }^{1,4}$
}

\begin{abstract}
Background: Childhood obesity has become an emerging urban health problem in urban cities in Bangladesh, particularly in affluent families. Risk factors for obesity in this context have not been explored yet. The objective of this study was to identify the risk factors associated with overweight and obesity among school children and adolescents in Dhaka, Bangladesh.

Methods: From October through November 2007, we conducted a case-control study among children aged 10-15 years in seven schools in Dhaka. We assessed body mass index (weight in kg/height in sq. meter) to identify the cases (overweight/obese) and controls (healthy/normal weight) following the Centers for Disease Control and Prevention age and sex specific growth chart. We used a structured questionnaire to collect demographic information and respondent's exposure to several risk factors such as daily physical activity at home and in school, hours spent on computer games and television watching, maternal education level and parents' weight and height.

Results: We enrolled 198 children: 99 cases, 99 controls. Multiple logistic regression analysis revealed that having at least one overweight parent $(\mathrm{OR}=2.8, \mathrm{p}=0.001)$ and engaging in sedentary activities for $>4$ hours a day $(\mathrm{OR}=2.0$, $p=0.02$ ) were independent risk factors for childhood overweight and/or obesity while exercising $\geq 30$ minutes a day at home was a protective factor $(O R=0.4, p=0.02)$. There were no significant associations between childhood overweight and sex, maternal education or physical activity at school.

Conclusion: Having overweight parents along with limited exercise and high levels of sedentary activities lead to obesity among school children in urban cities in Bangladesh. Public health programs are needed to increase awareness on risk factors for overweight and obesity among children and adolescents in order to reduce the future burden of obesity-associated chronic diseases.
\end{abstract}

Keywords: Risk factors, School children, Overweight, Obesity, Physical activity, Sedentary activity

\section{Background}

Childhood obesity is one of the major public health problems globally. During 2005, the prevalence of childhood overweight and obesity in high-income countries was $10.6 \%$ whereas in low-income countries, the prevalence was $5.2 \%$ [1-3]. Data from high- and low-income countries suggest that lack of physical activity, spending time on sedentary activities such as watching television

\footnotetext{
* Correspondence: mejbahubhuiyan@gmail.com

'James P Grant School of Public Health, Dhaka, Bangladesh

${ }^{2}$ Centre for Communicable Diseases, icddr,b, 68, Shaheed Tajuddin Ahmed

Sarani, Mohakhali, Dhaka 1212, Bangladesh

Full list of author information is available at the end of the article
}

and playing video games, low parental education, and family history of obesity are risk factors for childhood overweight and obesity [4-9]. Childhood obesity is a risk factor for several chronic diseases such as hypertension, type 2 diabetes, respiratory disease, and hepatic abnormalities and coronary heart diseases during adulthood $[10,11]$. Additionally, overweight and obesity affect selfesteem of children and impair social development $[12,13]$.

In Bangladesh, nearly $40 \%$ of children $<5$ years are suffering from malnutrition [14]. However, in recent years, multiple factors such as rapid urbanization, continually decreasing number of playgrounds, increasing purchasing power, and easy access to new technological devices

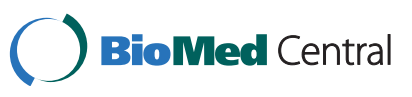


such as hand-held computer toys probably have lead to less physical activity and more sedentary activity, and thereby have attributed to an emerging overweight and obesity problem among young children in urban settings, especially among affluent families in Dhaka [15]. The country is now experiencing the double burden of malnutrition, with the existence of both undernutrition and overnutrition, in urban cities. Childhood overweight and obesity is a particular public health concern for Bangladesh because children who are overweight or obese have higher risk of becoming overweight or obese adults $[16,17]$ and overweight adults are at increased risk for mortality and morbidity with obesity-associated chronic diseases, which are already a burden to the struggling health system in Bangladesh [18,19].

Several studies suggest that schools are a potential setting to target both children and adolescent population for obesity prevention [20,21]. Identifying risk factors associated with overweight and obesity in school children would help to develop appropriate interventions to reduce the future burden of overweight and obesity among young population in Bangladesh. The objective of this study was to describe the risk factors associated with overweight and obesity among school children in Dhaka, Bangladesh.

\section{Methods}

\section{Study sites}

We conducted this study in seven schools located in Dhanmondi, Mohammadpur and Siddeswari area in Dhaka, Bangladesh during October through November 2007. The highest numbers of schools in Dhaka are situated in these places. We selected these schools based on three criteria: large number of students, having reputation for better education facility, and availability of play-ground within school premises. Each of seven schools was private and English was the medium of teaching in three of seven schools.

\section{Study design and study participants}

The study was designed as case-control study with cases being overweight children ${ }^{\mathrm{a}}$ and controls being healthy/ normal weight children. The study participants were students of age 10-15 years corresponding to class 5 to class 10 in the selected schools.

\section{Sampling size estimation}

We used EPI Info version 3.3 to calculate sample size for this study. Considering $80 \%$ power, $95 \%$ confidence level and case-control ratio $1: 1$, we calculated that 240 participants were required to detect at least 2 odds ratio differences between cases and controls.

\section{Case-control identification}

We adopted purposeful sampling method to select the cases and controls. The teachers at each school made initial selection of $12-15$ cases by visually assessing whether the students were overweight and also selected equal number of controls who visually seemed normal weight. Then, research assistants used standard procedures of anthropometry to measure standing height and weight (including shoes) of each primary selected participant and calculated body mass index (BMI) as weight in $\mathrm{kg} /$ height in meter ${ }^{2}$. Investigators used age- and sex-specific growth chart by the US Centers for Disease Control and Prevention [22] to categorize initially selected participant as cases or controls. Any participant falling into the underweight category according to growth chart was excluded from the study. We selected equal numbers of cases and controls from each school.

\section{Data collection}

We used a structured questionnaire to collect demographic information and information on exposures of interest: regular habit of physical activities, duration of sedentary activities which included watching television, use of computer and video games, and duration of sleep/day of each study participant. In order to know regular habit of physical activity, we asked participants to report how long did they spend every day in a typical week doing activities which require physical activity. These activities included playing games such as football, cricket and other outdoor games, running in field and cycling. WHO recommends to spend at least 60 minutes of physical activity per day for children aged 5-17 years [23]. Since we conducted this study among school children who might be involved in physical activities during their school stay, we split this recommended duration of physical activity per day into two bouts, in school and at home. We assumed that splitting the physical activity habit into school and home would give us the opportunity to have better understanding of actual physical activity pattern of students and also to help determining if any particular habit serves as risk factor for overweight problem in children. We asked the respondents to report the actual physical activity habit both in school and at home and we added to find the duration of total physical activity. We recoded the response into following categories: $<60 \mathrm{mi}-$ nutes and $\geq 60$ minutes per day for total physical activity and no time, $<30$ minutes and $\geq 30$ minutes per day for physical activity at home and school. Based on the median duration of sedentary activities per day of all participants, we categorized length of sedentary activities into two groups. We communicated over the phone with parents of each participant to obtain respondent's (case or control child) birth weight, parental weight and height to estimate BMI, and highest level of education completed by mother. 


\section{Data analysis}

We derived descriptive statistics to determine the distribution of demographic information including age, sex, education level, sleeping time, mother's highest level of education and BMI among case and control groups. For continuous data, we estimated mean (standard deviation, $\mathrm{SD})$ if the data were normally distributed or estimated median (interquartile range, IQR) otherwise. In order to compare mean or median of variables between cases and controls, we used $t$-test or Wilcoxon-rank sum test, respectively. We used Z-test to compare proportions between cases and controls. Initially, we determined association between outcome (overweight/obese) and exposure variables using simple logistic model (unadjusted model). Any exposure variable in simple logistic model with a beta coefficient at significant level 0.3 was selected for the multiple logistic regression model (adjusted model) [24]. We considered a p-value of $<0.05$ as significant level in multiple logistic regression model.

\section{Ethical considerations}

We obtained verbal informed consent to enroll students from the principals of respective schools followed by verbal consent from the parents of each participant before interviewing the participant. We obtained ethical clearance from BRAC University for conducting this study.

\section{Results}

Respondents' profile

From October through November 2007, we enrolled 198 students in this study; 99 cases and 99 controls. The participants were selected from class 5 to class 10 in order to tally with specific age groups. The mean age of study respondents was 13.1 years (SD: 1.2). Of 198 respondents, 107 (54\%) were male. The mean birth weight of respondents was 3.1 kilogram (SD: 0.8). The average sleeping time was 7.5 hours (SD: 1.0) and was similar across two groups. The median sedentary activities per day of all participants was 4 hours (IQR: 4-6). The median monthly household expenditure of respondents' families was US \$522 (IQR: 373-709). Eighty-five (44\%) of 198 respondents had at least one overweight parent. One hundred twenty-four (62\%) mothers reported to complete graduation degree or more (Table 1).

\section{Risk factors associated with overweight and obesity} Unadjusted regression model revealed that three factors were independently associated with overweight or obesity in children (Table 2). Having at least one overweight parent and spending $>4$ hours each day on sedentary activities such as watching television and/or computer games were risk factors for overweight or obesity. Physical activity at home for $\geq 30$ minutes each day was protective

Table 1 Demographic characteristics of study participants at seven selected schools in Dhaka, Bangladesh 2007

\begin{tabular}{|c|c|c|c|}
\hline \multirow[t]{2}{*}{ Characteristics } & \multirow{2}{*}{$\begin{array}{l}\text { Control } \\
\mathrm{N}=99\end{array}$} & \multirow{2}{*}{$\begin{array}{l}\text { Case } \\
\mathrm{N}=99\end{array}$} & \multirow[t]{2}{*}{$\mathrm{p}$ value } \\
\hline & & & \\
\hline Age in years, mean (SD) & $13.2(0.1)$ & $13.1(0.1)$ & $>0.05^{*}$ \\
\hline Male sex, n (\%) & $52(53)$ & $55(56)$ & $>0.05^{* * *}$ \\
\hline \multicolumn{4}{|l|}{ Participant's class, n (\%) } \\
\hline Five & $8(8)$ & $8(8)$ & $>0.05^{* * *}$ \\
\hline Six & $16(16)$ & $16(16)$ & $>0.05^{* * *}$ \\
\hline Seven & $27(27)$ & $24(24)$ & $>0.05^{* * *}$ \\
\hline Eight & $27(27)$ & $29(29)$ & $>0.05^{* * *}$ \\
\hline Nine & $20(20)$ & $21(21)$ & $>0.05^{* * *}$ \\
\hline Ten & $1(1)$ & $1(1)$ & $>0.05^{* * *}$ \\
\hline Birth weight in kg, mean (SD) & $3.2(0.7)$ & $3.0(0.8)$ & $>0.05^{*}$ \\
\hline Sleeping time/day, mean ((SD) & $7.7(1.0)$ & $7.4(1.0)$ & $>0.05^{*}$ \\
\hline BMI, mean (SD) & $18.5(2.4)$ & $28.8(3.6)$ & $<0.01^{*}$ \\
\hline Monthly family expenditure in US\$, median (IQR) & $522(373-597)$ & $522(448-746)$ & $>0.1^{* *}$ \\
\hline At least one overweight parent ${ }^{\S}, \mathrm{n}(\%)$ & $31(32)$ & $54(56)$ & $<0.00^{* * *}$ \\
\hline \multicolumn{4}{|l|}{ Maternal education } \\
\hline Up to higher secondary, $\mathrm{n}(\%)$ & $35(35)$ & $34(34)$ & $>0.05^{* * *}$ \\
\hline Graduation degree and more, $\mathrm{n}(\%)$ & $60(61)$ & $64(65)$ & $>0.05^{* * *}$ \\
\hline
\end{tabular}

${ }^{*} t$-test; ${ }^{* *}$ Wilcoxon-rank sum test; ${ }^{* * *}$ Z-test.

$\S \mathrm{BMI}$ of parents were assessed using self reported height $(\mathrm{m})$ and weight $(\mathrm{kg})$ of parents. BMI $>24.9$ was considered as overweight. 
Table 2 Risk factors associated with overweight and obesity among school children in Dhaka, Bangladesh 2007

\begin{tabular}{|c|c|c|c|c|}
\hline \multirow[t]{2}{*}{ Risk factor } & \multirow{2}{*}{$\begin{array}{l}\text { Control } \\
\text { n (\%) }\end{array}$} & \multirow{2}{*}{$\begin{array}{l}\text { Case } \\
\text { n (\%) }\end{array}$} & \multicolumn{2}{|c|}{ Odds ratio $(95 \% \mathrm{Cl})$} \\
\hline & & & Unadjusted & Adjusted \\
\hline \multicolumn{5}{|c|}{ Having at least one overweight parent } \\
\hline No & $66(68)$ & $43(44)$ & reference & reference \\
\hline Yes & $31(32)$ & $54(56)$ & $2.7(1.5-4.8)^{*}$ & $2.8(1.5-5.2)^{*}$ \\
\hline \multicolumn{5}{|l|}{ Total physical activities per day } \\
\hline$<60$ minutes $^{\dagger}$ & $64(65)$ & $69(70)$ & reference & Not included \\
\hline$\geq 60$ minutes & $35(35)$ & $30(30)$ & $0.80(0.4-1.4)^{\natural}$ & \\
\hline \multicolumn{5}{|l|}{ Physical activities at home per day } \\
\hline No & $13(13)$ & $27(27)$ & reference & reference \\
\hline$<30$ minutes & $28(28)$ & $27(27)$ & $0.5(0.2-1.1)^{\S}$ & $0.4(0.2-1.0)^{\S}$ \\
\hline$\geq 30$ minutes & $58(59)$ & $45(45)$ & $0.4(0.2-0.8)^{*}$ & $0.4(0.2-0.9)^{*}$ \\
\hline \multicolumn{5}{|l|}{ Physical activities at school per day } \\
\hline No & $40(40)$ & $43(43)$ & reference & \\
\hline$<30$ minutes & $26(26)$ & $22(22)$ & $0.8(0.4-1.6)^{\natural}$ & Not included \\
\hline$\geq 30$ minutes & $33(33)$ & $34(34)$ & $0.9(0.5-1.8)^{\natural}$ & \\
\hline \multicolumn{5}{|l|}{ Sedentary activities } \\
\hline $0-4$ hours & $59(60)$ & $41(40)$ & reference & reference \\
\hline$>4$ hours & $40(40)$ & $58(59)$ & $2.1(1.2-3.7)^{*}$ & $2.0(1.1-3.7)^{*}$ \\
\hline \multicolumn{5}{|l|}{ Sex } \\
\hline Female & $47(47)$ & $44(44)$ & reference & Not included \\
\hline Male & $52(52)$ & $55(56)$ & $1.1(0.6-2.0)^{\bullet}$ & \\
\hline \multicolumn{5}{|l|}{ Maternal education } \\
\hline Up to higher secondary & $35(37)$ & $34(35)$ & reference & Not included \\
\hline Graduation or more & $60(61)$ & $64(65)$ & $1.1(0.6-2.0)^{9}$ & \\
\hline Sleeping time & 99 (100) & $99(100)$ & $0.8(0.6-101)^{\natural}$ & Not included \\
\hline Monthly household expenditure & $99(100)$ & $99(100)$ & $1.0(1.0-1.0)^{\natural}$ & Not included \\
\hline
\end{tabular}

*p $<0.05 ;{ }^{\S} p>0.05 ;$ " $p>0.3$.

${ }^{*} \mathrm{p}<0.05 ; \mathrm{p}>0.05 ; \mathrm{p}>0.3$.
${ }^{\mathrm{T}}$ This group included 5 controls and 13 cases who reported no physical activity.

against childhood overweight or obesity. We did not find association between childhood overweight or obesity and duration of total physical activity for $\geq 60$ minutes per day, duration of physical activity at school, sex, or maternal education level and these variables were not included in multiple logistic model. The multiple logistic regression analysis showed that children who had at least one overweight parent were nearly three times more likely to be overweight or obese ( $\mathrm{OR}=2.8 ; 95 \%$ CI: 1.5-5.2) compared to children whose parents were not overweight, and children who spent $>4$ hours on sedentary activities each day were two times more likely to be overweight or obese than children who spent less time on sedentary activities $(\mathrm{OR}=2.0,95 \% \mathrm{CI}: 1.1-3.7)$. Children who spent $\geq 30$ minutes each day with outdoor games at home that involved physical exercise had decreased odds $(\mathrm{OR}=0.38,95 \% \mathrm{CI}$ : $0.1-0.8)$ of being overweight or obese compared to children who did not exercise at home (Table 2).

\section{Discussion}

Our data suggest that having overweight parent and engaging in sedentary activities including watching television and playing computer games for $>4$ hours a day were potential risk factors for childhood overweight or obesity, whereas regular physical activity at home for at least 30 minutes seemed to be a protective factor. To our knowledge, risk factors for overweight and obesity among young children in low-income countries including Bangladesh have not been explored previously. The findings of this study are consistent with previous studies from high and middle-income countries [4-6,9].

Our data demonstrated that having at least one overweight parent increased the likelihood of a child being overweight, a finding consistent with previous studies in middle- and high- income countries such as Brazil and Australia $[4,25]$. Genetic factors are considered as one of the risk factors for overweight and obesity in children [25]. However, the prevalence of childhood overweight 
and obesity in the urban areas in Bangladesh has increased only in the last few years, which might be too short a time for any significant genetic changes in the population [2]. While we did not collect data about food consumption practice of the study respondents, fast food consumption habit has been previously found as a potential risk factor for overweight and/or obesity among children [26]. We suspect that it could be the family dietary habit that contributes to weight gain among family members including young children.

Our data suggest that children who spent greater time in physical activities such as playing general outdoor games were less at risk for being overweight or obese although the association was not significant. We also identified that physical activity in school was not associated with being overweight or obese. This lack of association indicates students' tendency to be engaged in outdoor games in school. Since each of the study school had playing ground, the majority of students probably play sports during the games period. However, children who were less likely to be engaged in games at home or had little engagement time ( $<30$ minutes) were nearly three times more likely to be overweight, a finding consistent with previous studies $[5,9]$. The reduced physical activity of children during home-stay could be linked with the rapid urbanization of Dhaka where around 15 million people are currently residing. The city is expanding in all directions in response to the need for housing, leading to a reduction of open recreation spaces and therefore, probably contributing to a change in physical activity pattern of both children and adults. However, reduced space issue remained doubtful as the healthy children of this study were engaged in physical activities while residing in the same location. Further exploratory research among young children to understand physical activity practices including type of activities practiced would be useful to design effective public health programs that aim to promote physical activity in this setting.

Technological advances in the form of hand-held electronic devices and computer games, and television programs have probably contributed to adopt a lifestyle that involves to less physical activity and more sedentary activity [7]. A study conducted among children in Iran reported an association between watching television and being overweight [5]. The study demonstrated that watching television decreased the amount of time spent on playing outdoor games which might resulted in gaining extra weight. Another study in the US reported that watching television or videos for $>2$ hours a day increased the risk of being overweight in children [27]. In this study, we combined the time spent on watching television and using computers per day, and found that overweight children spent more time ( $>4$ hours) on sedentary activities compared to healthy children.
Studies conducted in Brazil and Iran have reported lower educational status of mother as a risk factor for overweight and obesity in children [4,5]. However, in this study we found that mothers of overweight and obese children were more educated than mothers of healthy children, although the association was not significant. One hypothesis to explain this contrasting finding could be related to respondents' socioeconomic status. As the respondents were selected from the schools in middle class residential areas, more mothers were likely fall into the highly educated category (graduate and more).

\section{Limitations}

Several limitations of this study should be noted. One important limitation was the relatively short duration, 2 months, for data collection which resulted in lower than estimated respondent enrollment which could reduce study power. However, the majority of our findings were consistent with previously published reports, suggesting that lower sample size likely had little impact on our assessment. We did not use any previously validated physical activity questionnaire to measure physical activity of study participants. Use of valid questionnaire could provide robust assessment of physical activity habit and it's relationship with risk of overweight or obesity. However, the list of activities that we used to measure physical activity of children included those that Bangladeshi children used to do in this context. Yet, the importance of using validated physical activity questionnaire cannot be ignored. We did not collect data on individual games they played at home or in school rather we asked them to report us their engagement in the activities that we included in the list (e.g. football, cricket, and other outdoor games, running and cycling). Therefore, we could not inform if the activities done at home by the healthy children (controls) were likely to be of a higher intensity compare to overweight or obese children (cases). The cases were selected by teacher's visual assessment. Therefore, it could happen that the most overweight children in the class were selected. However, as we found that the BMI of cases were normally distributed (data not shown), we suspect visual selection of cases might had modest impact on study outcome. Although it would be ideal to assess height and weight of parents, since the interviews were time-consuming and conducted after school hours, we communicated with each parent over the telephone and relied on self-reported anthropometric measurement of parents. Therefore, the possibility of error during measurement of height and weight remained valid. We conducted this study in seven schools in Dhaka city. So, the risk factors that we identified may not be representative of every urban city in Bangladesh. 


\section{Conclusions}

Our study demonstrated that several risk factors such as having overweight parent, limited physical exercise at home and high levels of sedentary activities are associated with overweight and obesity among urban school children in Dhaka, Bangladesh. Public health programs are warranted to increase awareness on these risk factors among children and adolescents in order to reduce the future burden of obesity-associated chronic diseases. Among different settings, schools should be the priority setting to target both children and adolescents because it offers momentous opportunities for prevention.

\section{Endnotes}

a"Overweight children" included those who were obese.

\section{Competing interests}

The authors declare that they have no competing interests.

\section{Authors' contribution}

MUB, SZ and TA designed the study. MUB coordinated data collection, extracted the data, performed statistical analysis, and drafted the manuscript. SZ and TA revised the manuscript and provided comments and suggestions. All authors read and approved the final version.

\section{Acknowledgements}

The authors acknowledge the support of faculties of James P. Grant School of Public Health (JPGSPH), BRAC University, especially Dr. Richard Cash, Dr. Sabina Faiz Rashid for this research. We highly appreciate the support of the principles of study schools for conducting this research at their schools and the efforts of Ms. Tasmina Rahman, Md. Abul Bashar and Mr. Abid Azad who assisted with data collection. We greatly acknowledge support of our study participants and the parents. We thank Meghan Scott for assisting in the development of the manuscript.

\section{Author details}

${ }^{1}$ James P Grant School of Public Health, Dhaka, Bangladesh. ${ }^{2}$ Centre for Communicable Diseases, icddr,b, 68, Shaheed Tajuddin Ahmed Sarani, Mohakhali, Dhaka 1212, Bangladesh. ${ }^{3}$ Institute of Health and Society, Newcastle University, Baddiley-Clark Building, Richardson Road, Newcastle upon Tyne NE2 4AX, UK. ${ }^{4}$ Centre for Nutrition and Food Security, icddr,b, 68, Shaheed Tajuddin Ahmed Sarani, Mohakhali, Dhaka 1212, Bangladesh.

Received: 23 October 2012 Accepted: 3 May 2013

Published: 8 May 2013

\section{References}

1. de Onis M, Blossner M, Borghi E: Global prevalence and trends of overweight and obesity among preschool children. Am J Clin Nutr 2010, 92:1257-1264

2. Lobstein $T$, Baur L, Uauy R: Obesity in children and young people: a crisis in public health. Obes Rev 2004, 5(Suppl 1):4-104.

3. Wang Y, Lobstein T: Worldwide trends in childhood overweight and obesity. Int J Pediatric Obesity 2006, 1:11-25.

4. Giugliano R, Carneiro EC: Factors associated with obesity in school children. J Pediatr (Rio J) 2004, 80:17-22.

5. Mozaffari H, Nabaei B: Obesity and Related Risk Factor. Indian J Pediatr 2007, 74:265-267.

6. Salmon J, Campbell KJ, Crawford DA: Television viewing habits associated with obesity risk factors: a survey of Melbourne school children. MJA 2006, 184:64-67.

7. Singh AK, Maheshwari A, Sharma N, Anand K: Lifestyle associated risk factors in adolescents. Indian J Pediatr 2006, 73:901-906.

8. Singh M, Sharma M: Risk factors for obesity in children. Indian Pediatr 2005, 42:183-184

9. Veugelers PJ, Fitzgerald AL: Prevalence of and risk factors for childhood overweight and obesity. CMAJ 2005, 173:607-613.
10. Aronne LJ: Classification of obesity and assessment of obesity-related health risks. Obes Res 2002, 10(Suppl 2):105S-115S.

11. Dietz WH: Overweight in childhood and adolescence. N Engl J Med 2004 350:855-857.

12. Friedlander SL, Larkin EK, Rosen CL, Palermo TM, Redline S: Decreased quality of life associated with obesity in school-aged children. Arch Pediat Adolesc Med 2003, 157:1206-1211.

13. Hesketh $\mathrm{K}$, Wake $M$, Waters E: Body mass index and parent-reported self-esteem in elementary school children: evidence for a causal relationship. Int J Obes Relat Metab Disord 2004, 28:1233-1237.

14. Ahmed T, Ahmed AMS: Reducing the burden of malnutrition in Bangladesh. BMJ 2009, 339:b4490.

15. Ahmed SMM, Islam MS, Razzaque A, Ahmed T: Socioeconomic differentials of childhood obesity among school children in the context of affluent society of Dhaka City. In 11th Annual Scientific Conference (ASCON). Dhaka, Bangaldesh: icddr,b; 2007:129.

16. Singh AS, Mulder C, Twisk JW, van Mechelen W, Chinapaw MJ: Tracking of childhood overweight into adulthood: a systematic review of the literature. Obes Rev 2008, 9:474-488.

17. Whitaker RC, Wright JA, Pepe MS, Seidel KD, Dietz WH: Predicting obesity in young adulthood from childhood and parental obesity. N Engl J Med 1997, 337:869-873.

18. Bangladesh Bureau of Statistics: Statistical Pocketbook of Bangaldesh 2007. Dhaka, Bangladesh: Bangladesh Bureau of Statistics; 2007.

19. Mirelman A, Koehlmoos TP, Niessen L: Risk-attributable burden of chronic disease and cost of prevention in Bangladesh. Global heart 2012, 7:61-66.

20. Gortmaker SL, Peterson K, Wiecha J, Sobol AM, Dixit S, Fox MK, Laird N: Reducing obesity via a school-based interdisciplinary intervention among youth: Planet Health. Arch Pediatr Adolesc Med 1999, 153:409-418.

21. Wang LY, Yang $\mathrm{Q}$, Lowry $\mathrm{R}$, Wechsler $\mathrm{H}$ : Economic analysis of a school-based obesity prevention program. Obes Res 2003, 11:1313-1324

22. Clinical Growth Charts. [http://www.cdc.gov/growthcharts/clinical_charts.htm].

23. Physical activity and young people. [http://www.who.int/dietphysicalactivity/ factsheet_young_people/en/index.html].

24. Bursac Z, Gauss CH, Williams DK, Hosmer DW: Purposeful selection of variables in logistic regression. Source Code Biol Med 2008, 3:17.

25. Gibson LY, Byrne SM, Davis EA, Blair E, Jacoby P, Zubrick SR: The role of family and maternal factors in childhood obesity. MJA 2007, 186:591-595.

26. Niemeier HM, Raynor HA, Lloyd-Richardson EE, Rogers ML, Wing RR: Fast food consumption and breakfast skipping: predictors of weight gain from adolescence to adulthood in a nationally representative sample. $J$ Adolesc Health 2006, 39:842-849.

27. Mendoza JA, Zimmerman FJ, Christakis DA: Television viewing, computer use, obesity, and adiposity in US preschool children. Int J Behav Nutr Phys Act 2007, 4:44.

\section{doi:10.1186/1471-2431-13-72}

Cite this article as: Bhuiyan et al.: Risk factors associated with overweight and obesity among urban school children and adolescents in Bangladesh: a case-control study. BMC Pediatrics 2013 13:72.

\section{Submit your next manuscript to BioMed Central and take full advantage of:}

- Convenient online submission

- Thorough peer review

- No space constraints or color figure charges

- Immediate publication on acceptance

- Inclusion in PubMed, CAS, Scopus and Google Scholar

- Research which is freely available for redistribution 